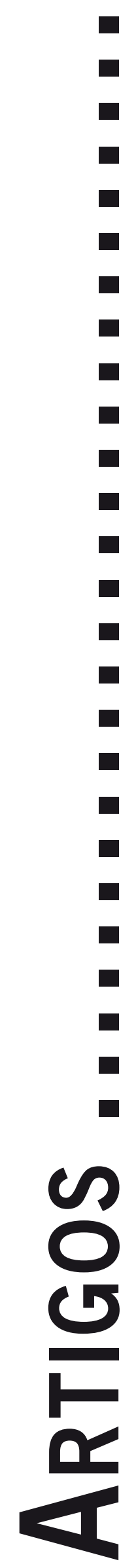




\title{
REFLEXÕES SOBRE O CONTRATO TERAPÊUTICO COMO INSTRUMENTO DE AUTORREGULAÇÃO DO TERAPEUTA ${ }^{1}$
}

\author{
Reflections about the Therapeutical Contract as a Self Regulating Instrument for the Therapist \\ Reflexiones sobre el Contrato Terapéutico como Instrumento de Autorregulación del Terapeuta
}

Gladys Costa de Moraes RêGo Macedo D`Acri

\begin{abstract}
Resumo: Este artigo visa amplificar a função do contrato terapêutico para além de uma combinação de dados objetivos. A partir do que acontece nos primeiros encontros entre terapeuta e cliente, os rumos desta relação poderão ser traçados. Inserido neste contexto, está o contrato terapêutico, cujas cláusulas, quando em consonância com as necessidades atuais do profissional, poderão contribuir para evitar os danos à relação como descontentamento, interrupção, abandono ou, até mesmo, o cancelamento do tratamento por qualquer uma das partes. Como mais um cuidado na construção desta relação, a autora propõe o contrato escrito, apresentando seu modelo e tecendo comentários reflexivos às suas cláusulas contratuais.

Palavras-chave: Atualização; Autorregulação; Contrato terapêutico; Cristalização; Gestalt-terapia.
\end{abstract}

\begin{abstract}
The presented article proposes to take the therapeutic contract beyond the combination of objective data. The development of the relationship between therapist and client is shaped during the first meetings. In this context the therapeutic contract contributes to this relationship. The contract can, if it considers the current needs of the professional, prevent that the relationship gets damaged due to dissatisfaction, interruption, abandonment, or stopping treatment all together. The author suggests to set up a written contract as an additional mechanism to build this relationship and presents her model and contract details.

Keywords: Crystallization; Gestalt-therapy; Self-regulation; Therapeutic contract; Updating.

Resumen: La proposición de este artículo es de ampliar la función del contrato terapéutico para que sea más que una combinación de datos objetivos. De lo que ocurre en los primeros encuentros entre el terapeuta y el cliente es que la dirección de esta relación se remonta. En este contexto está el contrato terapéutico cuyas cláusulas, cuando em consonancia con las necesidades actuales del profesional, podrán ayudar a evitar daños a la relación como el descontentamiento, la interrupción, el abandono o, incluso, el cancelamiento del tratamiento por una de las partes. Como una otra precaución para la construcción de esta relación, la autora propone el contrato escrito, presentando su modelo e exponiendo sus comentarios reflexivos a sus cláusulas contractuales.

Palabras-clave: Actualización; Autorregulación; Contrato terapêutico; Cristalización; Terapia Gestalt.
\end{abstract}

"O contato pode nos trazer muita dor.

E traz. Mas é dor de nascimento e crescimento, que, logo ou mais adiante, vai fazer a magia da liberdade".

(Casarin, 2008).

\section{Introdução}

Pouco destaque se dá ao contrato terapêutico nas formações, especializações e estágios de qualquer abordagem psicológica, conforme denota a quantidade ínfima de trabalhos sobre o assunto na literatura em Psicologia. No entanto, este instrumento é o marco que estabelece

\footnotetext{
Parte do conteúdo deste trabalho foi apresentada no XI Encontro Nacional de Gestalt-terapia e VIII Congresso Nacional da Abordagem Gestáltica, realizado em 2007, no Rio de Janeiro. Para a dinamização deste fórum interativo foram convidadas Izabel Pitanga e Sheila Orgler, a quem dedico este trabalho.
}

uma relação de compromisso e visa delinear os princípios norteadores do espaço terapêutico, mas quando pouco esclarecido por quem o propõe, no caso, o terapeuta, poderá provocar efeitos danosos à relação terapêutica. Em vista disso, este artigo pretende discutir questões envolvidas no contrato terapêutico que possam contribuir para o desequilíbrio nesta relação que está se estabelecendo.

Num segundo momento, a autora relata a sua experiência com contratos por escrito, propondo-os como um registro da combinação verbal entre terapeuta e cliente, estabelecida no momento da decisão pelo tratamento psicoterápico. Embora não seja o intento, alguns pontos podem parecer polêmicos, porém, na visão da autora, é de suma importância serem mencionados para uma reflexão mais abrangente sobre a ética do terapeuta diante do seu trabalho clínico, principalmente no foco que direciona este trabalho, ou seja, o momento inicial, quando um novo cliente está sendo aceito. 
Em suas considerações, a autora enfatiza a necessidade de ampliar a função do contrato terapêutico para além de uma combinação de dados objetivos, propondo a sua utilização como um instrumento de autorregulação para o terapeuta.

\section{A Autorregulação do Terapeuta}

Quando se conclui uma formação/especialização e se pretende ingressar na clínica, elege-se frequentemente as figuras dos coordenadores, dos supervisores e do próprio terapeuta como modelos. Para a Gestalt-terapia, isto significa que parte do suporte, principalmente do terapeuta iniciante, está nestas figuras que, por sua vez, representam o apoio ambiental.

As necessidades de mudanças acompanham o crescimento profissional, sendo assim o terapeuta assume, paulatinamente, atitudes diferentes ao experimentar e assimilar a novidade na sua relação com o meio. Muitas vezes, o que permitia ou tolerava no início da clínica profissional, posteriormente pode assumir novos posicionamentos, como, por exemplo, não aceitar a maioria dos clientes que o procura, menos condescendência na valoração do próprio trabalho e outras posturas que serão comentadas mais adiante. Esta evolução é a descrição do que Perls (1977) chamou de maturação: "um processo de crescimento contínuo, onde o apoio ambiental é transformado em auto-apoio" (p. 33).

Alguns fatores contribuem para a construção do autossuporte, são eles: a chegada de novos clientes, supervisão de casos clínicos, experiência de vida e, fundamentalmente, na visão desta autora, a psicoterapia pessoal. Segundo Perls, (conforme citado por Lima, 2005) “um dos papéis da psicoterapia era promover uma maior fluidez no funcionamento saudável da pessoa através do resgate do seu próprio mecanismo de auto-regulação organísmica” (p. 208). Por auto-regulação organísmica entende-se o processo de percepção da necessidade dominante, a qual se transforma em uma figura, cuja satisfação o organismo busca na interação com o meio, possibilitando o reinício deste ciclo. Por conseguinte, pressupõe-se que o terapeuta, a partir do seu processo pessoal de terapia, exerça a autorregulação de maneira consciente, hierarquizando suas necessidades, incluindo as profissionais, evidentemente. Desta forma, atento às necessidades, percebe os momentos em que busca, na interação com seu cliente, a satisfação de algumas delas.

\section{O Contrato Terapêutico e suas Implicações}

Na literatura gestáltica, pouco se escreve e se fala sobre o contato inicial do cliente e terapeuta. No entanto, paradoxalmente, é a partir do que acontece nestes primeiros encontros que os rumos desta relação poderão ser traçados. Parece estranho não se dedicar atenção a este período em que ambos, terapeuta e cliente, estão envolvidos no processo de escolha mútua. De um lado, o cliente que chega com suas expectativas, frustrações, jogos, sintomas e do outro, o terapeuta, com sua disponibilidade, experiência (quando já tem), expectativa, embasamento teórico e todos os problemas da vida de qualquer ser humano.

Inserido no contexto dos primeiros encontros entre terapeuta e cliente, está o contrato terapêutico, valioso instrumento que deve permanecer em consonância com o terapeuta e por isto pode sofrer modificações à medida que ele [terapeuta] cresce e se atualiza. Implicada nesta ideia recorre-se a dois conceitos utilizados pela Gestaltterapia, cristalização e atualização, e que estão intrinsecamente ligados à autorregulação organísmica.

Na medida em que o organismo não é capaz de identificar a figura dominante, também não busca a satisfação, ocasionando a cristalização da mesma, impedindo assim o fluxo natural do processo de figura e fundo. Em contrapartida, a atualização acontece toda vez que o organismo satisfaz a necessidade premente. Assim, o terapeuta que identifica suas necessidades e encontra recursos para satisfazê-las poderá proporcionar meios de crescimento, ao cliente, com o fluir da relação; o cliente, da mesma forma, ao assimilar esta ideia, poderá na relação com o seu terapeuta buscar a satisfação de algumas das suas necessidades genuínas, se utilizando inclusive do contrato terapêutico, quando for o caso. Conforme afirma Yontef (1998), "um terapeuta cujo contato é orientado por awareness clara consegue fazer discriminações que irão combinar de forma otimista com as necessidades terapêuticas do paciente" (p.365).

Qualquer contrato, seja ele de que natureza for, é um ato bilateral, com deveres e direitos, que assume uma função reguladora para as partes e, por isto, poderá sofrer alterações à medida que se torna obsoleto como regente do motivo de sua existência. Logo, as cláusulas deverão ser pensadas levando-se em conta as necessidades dominantes e, quem as aceita, concordará em cumpri-las para que o equilíbrio seja mantido. Todavia, o meio externo é um poderoso agente eliciador das mudanças, capaz de alterar cláusulas ou até todo o contrato mesmo quando as partes não sentem a necessidade de mudanças. Um exemplo foi o Plano Collor que propiciou alterações drásticas nos contratos, inclusive os terapêuticos.

Segundo o dicionário Michaelis (versão online), uma das definições sobre contrato versa: "acordo ou convenção entre duas ou mais pessoas, para a execução de alguma coisa, sob determinadas condições". Ora, o contrato terapêutico é também "um acordo entre duas [terapeuta e cliente] ou mais pessoas [grupo, casal, família etc.], para a execução de alguma coisa [psicoterapia], sob determinadas condições [cláusulas do contrato]”.

Lima Filho (1995), em seu artigo intitulado "O Contrato Terapêutico” apresenta a seguinte definição: “um 
trato que se faz com, de onde se deduziria que cliente e psicoterapeuta estariam definindo em comum acordo as regras e responsabilidades recíprocas que irão reger seu trabalho" (p. 77).

Especificamente no contrato terapêutico deve-se atentar para as cláusulas, pois, muitas vezes, quando há desigualdade ou desequilíbrio no ato de contratar, isto refletirá posteriormente na relação terapêutica sob forma de descontentamento - expresso em faltas, agressividade, desmarcações, desconfiança, dentre outras - ou até mesmo a interrupção, o abandono e o cancelamento do tratamento.

Muitos terapeutas parecem temer o uso do controle deste instrumento e se submetem às cláusulas impostas pelo cliente como preços determinados por eles, malabarismo nas agendas, período de férias em que o cliente goza e o terapeuta é, muitas vezes, privado da remuneração porque no seu contrato possui uma cláusula apenas para as férias do cliente.

Conceder significa dar, outorgar, permitir, facultar, logo quem concede pode estar, paradoxalmente, assumindo instantaneamente uma dívida na relação; con-ceder é diferente de negociar e negociar precisa ser con-trato.

É necessário considerar que quando o terapeuta se sente compelido a conceder algum pedido do seu cliente, neste período de escolha mútua, e se esta concessão significa infringir as cláusulas do seu próprio contrato, ao fazê-lo, poderá causar futuramente dano à relação. Algumas formas de expressar estes danos são: atrasos com o cliente anterior, sonolência, desmarcações etc. Também o contrário acontece: o cliente que aceita as condições de maneira tão concordata e sem negociação que, posteriormente, infringe o acordo atrasando o pagamento, solicitando frequentemente mudanças de horário etc.

Deve-se atentar que o contrato terapêutico é para ser feito com todos os clientes, inclusive aquele que também é psicólogo. Muitas vezes, alguns terapeutas negligenciam estes pretensos clientes quando deixam de propor o contrato com todas as suas cláusulas, baseando-se que o "colega" as conhece por exercer a mesma profissão. Segundo esta autora, se a Gestalt-terapia considera o homem singular, logo o contrato terapêutico precisa ser personalizado e explicitado com cada cliente, independente da profissão exercida pelo mesmo. Não se pode esquecer de que o cliente-psicólogo está ali para ser cuidado e não para exercer a sua profissão, embora possa ter uma compreensão maior. Infelizmente isto é mais comum do que deveria, e independe do tempo de experiência do terapeuta; pode este descuido se transformar posteriormente em uma resistência ou até impedir o início da relação.

Considera-se tarefa do terapeuta, que se mantém em consonância consigo mesmo e com esta abordagem, modificar, experimentar e introduzir novas cláusulas em seus contratos, toda vez que identificar insatisfações e desigualdades no contratar e ser contratado. Com isto, o contrato terapêutico aspira ser um recurso do qual o terapeuta poderá fazer uso para estabelecer, por meio de suas cláusulas, as combinações com o cliente, baseado, inicialmente, em suas necessidades, revistas e atualizadas, durante este período de entrevistas.

Até mesmo o cliente que por algum motivo precisou interromper o tratamento e quer retornar para a terapia com o mesmo terapeuta deverá ter um novo contrato, pois se uma das propostas é usar este instrumento como autorregulador das necessidades, a fim de se evitar, por exemplo, os danos à relação, então o terapeuta deverá rever o seu contrato anterior à interrupção para atualizá-lo e manter-se consoante com as suas necessidades atuais e possibilitar o mesmo para o cliente.

Quando o terapeuta não identifica suas necessidades pessoais a cada cliente que entrevista, quando não percebe qual necessidade [sua] que precisa ser atendida, corre o risco de aceitar como único modelo o velho contrato aprendido na época da faculdade: cláusulas pré-fixadas, cujo objetivo é formalizar o tratamento, sem levar em conta em que momento está sendo estabelecido e as necessidades do terapeuta/cliente. Este contrato, na verdade, é uma minuta contratual terapêutica, ou seja, um rascunho resumido que precisa ser atualizado e personalizado.

Adicionalmente, é importante salientar que um contrato poderá sofrer alterações a qualquer momento do processo terapêutico, como por exemplo, mudança no número de sessões, atualização de valores mediante algum fator externo não previsto anteriormente, inclusão de cláusula nova etc. Caso não haja abertura para isto, incorrerá na rigidez e cristalização. Lima Filho (1995) concorda que "mudanças na vida do cliente, ou do terapeuta, podem requerer alterações contratuais" e acrescenta:

Quaisquer novidades apresentam-se como gratas oportunidades para que se faça um balanço, mesmo informal, do andamento da psicoterapia até aquele momento, ou simplesmente uma retomada do contrato para incluir o dado novo. Esses momentos ritualizam algo muito importante: a reescolha daquela parceria para a continuidade do trabalho (p.85).

\section{Planejamento do Terapeuta e Ética Profissional}

"Para que estou marcando esta entrevista?" "Tenho um projeto novo?" "Preciso de dinheiro?" "Perdi um cliente e necessito ocupar o horário?" Estas são algumas das perguntas que o terapeuta deve fazer a si mesmo, pois o desejo de ter um cliente é como a gestação de um bebê: não começa na concepção propriamente dita e, sim, no momento do planejamento, consciente ou não, dos pais. Portanto, não começa no ato de contratar e, sim, no planejamento do terapeuta quando, por exemplo, disponibiliza um horário porque um cliente foi embora ou porque tem um novo projeto e precisa aumentar sua receita. A necessidade de autorregulação do terapeuta favorece aceitar um cliente que nem conhece como se evidenciou acima. 
Na verdade, o grande questionamento é que frequentemente acredita-se que somente diante do cliente que o escolhemos, mas uma das questões que este trabalho discute é se esta escolha, por vezes, não ocorre anteriormente, mais precisamente no planejamento do terapeuta.

Em vista disso, esta escolha do terapeuta por um cliente pode ter critérios diferentes, como se verifica em algumas situações a seguir. Quando o terapeuta atende uma pessoa no horário que designa como nobre² poderá criar critérios mais rigorosos, como não negociar o seu preço, por exemplo, em detrimento daquele ao qual atende num horário menos procurado. Quando dois clientes deixam a terapia numa mesma época, a avaliação para a inclusão de outros pode ser menos exigente. Portanto, a flexibilidade para aceitação dos novos clientes possivelmente dependerá de diversos critérios.

Uma clínica mais estabelecida e a maturidade profissional são fatores que podem favorecer uma escolha mais exigente, isto é, um "não" mais consciente ao que de antemão o terapeuta reconhece como limites para aceitação de um cliente. Contudo, isto não o isenta de acreditar que a escolha seja só pelo cliente, pela identificação ou por qualquer outro motivo. E esta é uma das proposições deste artigo: a escolha por um cliente é em sua maioria baseada nas necessidades do terapeuta.

Assim como é conhecido o cliente-sedutor, o terapeuta também pode se utilizar da sedução para angariar o pretenso cliente, principalmente nas situações descritas anteriormente. Quando não está consciente destas necessidades, acreditará que sua escolha é unicamente pela identificação com o cliente e o tratamento poderá sofrer danos, conforme já mencionados. Legitimar estas necessidades é assumir uma postura ética consigo mesmo e com quem o procura.

É importante não se perder de vista que o contexto dos questionamentos deste artigo diz respeito aos primeiros encontros com o pretenso cliente, portanto, antes do fechamento do contrato, e sua ênfase aponta a figura do terapeuta.

A permissão do próprio profissional em compreender que um contrato terapêutico precisa ser atualizado é que pode legitimar o que foi chamado neste trabalho de planejamento do terapeuta, compreendido aqui como a expressão da sua autorregulação. O que se propõe é a valorização do contrato terapêutico como um instrumento de conscientização para o terapeuta das suas próprias necessidades e, à medida que sua proposição significa o início do processo terapêutico, então o profissional terá tempo de perceber quando busca na interação com o pretenso cliente a satisfação de algumas delas. Como diz Yontef (1998), "a segurança e a qualidade de uma te-

\footnotetext{
2 Expressão utilizada para designar horários privilegiados na agenda do terapeuta em função da procura dos pretensos clientes ser maior por causa dos seus próprios horários de trabalho. Habitualmente são os primeiros horários da manhã, a hora do almoço e a partir das $18 \mathrm{~h}$.
}

rapia dependem, em parte, da qualidade das discriminações feitas pelo terapeuta" (p. 365).

\section{Contrato Escrito}

Outro objetivo da proposição deste trabalho diz respeito a mais uma definição sobre contrato encontrada no dicionário Michaelis (versão online): "2- documento em que se registra esse acordo ou convenção".

Há muito tempo que adotei o contrato na forma escrita com meus clientes. Inicialmente foi uma maneira encontrada para esclarecer o funcionamento do programa de atendimento a quem contratava o serviço de spa urbano da minha clínica, o qual envolvia uma equipe multidisciplinar, inclusive o atendimento psicológico. Posteriormente, direcionou-se para atendimentos exclusivamente de psicoterapia. Gradativamente percebi que aquele documento era mais do que um esclarecimento, por si só exercia uma função de controle para ambas as partes. No início de um tratamento, este controle é mais necessário por parte do terapeuta. Perls (1980) já o anunciava quando descreveu o controle como sendo uma das cinco epígrafes ${ }^{3}$ das tarefas do terapeuta. Por controle entendia:

(...) a capacidade do terapeuta de persuadir ou compelir o paciente a obedecer aos procedimentos que ele fixou (...). O controle é de suma importância no início da terapia. A necessidade de controle diminui com o incremento do controle cooperante do paciente e do terapeuta, em virtude da maior capacidade de comunicação na linguagem um do outro e do desenvolvimento da confiança (p. 128-132).

Existem momentos alternados para este exercício de controle e descobri um importante experimento para ambos, terapeuta e cliente, apenas com o registro por escrito do que é expresso também verbalmente. Do ponto de vista do terapeuta, há a possibilidade de aprender a exercer o controle necessário sem o domínio. E do enfoque do cliente, pode ser um verdadeiro exercício de vigilância, de comprometimento, de controle, mas sem dominação. Compreende-se por domínio, o sentido (ou desejo) de propriedade e autoridade sobre o outro.

Outro objetivo do contrato por escrito é imprimir um rito de passagem a este momento tênue em que a relação está sendo assumidamente iniciada, mas que não está ainda constituída. Já escutei frases como "caramba, agora é sério" ou "agora não posso sair"? ou de uma advogada "... mas, isto não tem efeito legal, nenhum", ou outros que, simplesmente, após a leitura e a assinatura, guardam na bolsa como algo natural. Cada um expressa o que tem a ver com a sua vida, com o seu fundo de ex-

\footnotetext{
As demais são: padronização, potência, humanidade e comprometimento.
} 
periências, emergindo daí, por vezes, material para ser trabalhado.

Do meu lado, esta proposta de contrato por escrito, surge de minha vivência como filha de advogado/contador para estas profissões o acordo verbal não tem valor legal - o qual repetidamente expressava como princípio para seus clientes: "um bom contrato é aquele que oferece deveres e direitos, em igual proporção, para ambos os lados".

Compreendendo o contrato escrito como a transcrição do que é combinado verbalmente, um aspecto a ser considerado para justificar a sua relevância diz respeito à quantidade de informações que o cliente recebe ao mesmo tempo. Quem propõe as cláusulas é o terapeuta, logo ele as conhece e repete muito mais vezes do que o cliente as escuta. E isto não é uma desigualdade?

No meu procedimento reservo um tempo para conversar sobre os rumos que se irá tomar, ao final da primeira entrevista. Havendo concordância para marcar um segundo encontro, então se expõem verbalmente algumas informações básicas como preço, horário e sobre as faltas, para que o cliente tenha mais elementos para avaliar a escolha que está fazendo.

No encontro seguinte, ou quando for decidido que haverá continuidade, discuto as cláusulas de todo o contrato, sendo comunicado que na sessão subsequente será apresentado, por escrito, o que foi combinado naquele momento. Antes da assinatura, proponho a leitura. Os contratos possuem duas vias, sendo uma entregue ao cliente.

Como a minha clínica é composta por adolescentes e adultos, os menores de idade também assinam o contrato terapêutico. Normalmente faço a primeira entrevista com o adolescente e depois com os pais. Quando decidimos que iremos trabalhar juntos, converso sobre o contrato com o adolescente e depois com os seus responsáveis que assinam junto com o filho.

Consta no site do CRP-08 (Paraná), um modelo de contrato por escrito, embora diferente do que proponho. Não se deve perder de vista os aspectos personalístico e criativo de um contrato, principalmente por escrito. Estes aspectos contribuem para um exercício de contato, por um lado, para que o terapeuta esteja consciente de suas necessidades ao fixar as cláusulas e, por outro, para que o cliente exponha suas particularidades, discordar, tirar suas dúvidas, comentar e, ambos, chegando a um acordo, assumirem a responsabilidade pela escolha que estão fazendo.

Portanto, somente depois de transcorridas as combinações verbais é que se pode elaborar a sua forma escrita. Caso contrário, sendo um único modelo escrito para todos os clientes, concorre para a cristalização, assemelhando-se ao que chamei anteriormente de minuta contratual, isto é, um rascunho que precisa ser atualizado e personalizado.

É importante ressaltar que não está sendo proposta à existência do contrato escrito como primordial no estabe- lecimento da contratação e muito menos para o sucesso do tratamento. O fundamental, como já foi dito, é o contato que o terapeuta deve fazer consigo mesmo quando está aceitando um cliente a fim de se manter consoante com suas necessidades atuais e entender que uma contratação não deverá ser feita automaticamente.

\section{Cláusulas Contratuais}

A seguir serão comentadas apenas algumas cláusulas de um dos modelos de contrato que adoto atualmente, pois, a meu ver, estas cláusulas são as que mais suscitam dúvidas no exercício da clínica sendo, por isto, que a numeração do texto possui interrupções. No Anexo 1, o leitor encontrará a íntegra do modelo de contrato apresentado.

Cláusula 1: "A consulta psicológica tem duração de até 60 minutos";

Comentários: a awareness será valorizada como o objetivo das sessões. Comunico ao cliente que até as sessões muito mobilizantes, não serão prolongadas por conta do tempo que ainda não acabou e explico a importância de ficar em contato com o material resultante da sessão.

Perls (conforme citado por Müller-Granzotto \& MüllerGranzotto, 2007) não se preocupava com este tempo cronológico, porém encerrava um trabalho "tão logo uma forma de ajustamento criativo fosse flagrada e dela o participante se apercebesse, ou um ajustamento criador fosse estabelecido para a surpresa do próprio consulente, o atendimento era encerrado" (p. 320).

Na minha prática clinica, o próprio cliente muitas vezes pede espontaneamente para ir embora, sem ficar olhando para o relógio. Entretanto, são comuns alguns clientes, por exemplo, que nunca fizeram terapia ou aqueles que ainda estão iniciando o trabalho, ficarem preocupados com o tempo cronológico. "O tempo de sessão é, portanto, o tempo de revelação de uma Gestalt em que há manifestação de uma inibição reprimida, ou a superação dela" (Müller-Granzotto \& Müller-Granzotto, 2007, p. 320).

Aos terapeutas iniciantes, é importante comunicarlhes que por vezes se tem a sensação de que a sessão não foi produtiva. No entanto, tempos depois constatamos que o cliente teve uma percepção diferente.

Cláusula 4: "O cliente paga por um horário regular previamente combinado com seu terapeuta, por isto é cobrado mesmo em caso de falta justificada";

Comentários: não desmarco sessões e, sim, as remarco. O cliente é avisado que ele assume um compromisso semanal, sendo assim, mesmo que não possa estar presente por qualquer motivo, pagará pela sessão. Se acontecer de uma remarcação ficar para o mês seguinte, 
o cliente é avisado que esta sessão será paga no mês em que deveria ter sido feita.

Se o terapeuta não estabelecer cláusulas para cuidar do seu planejamento poderá ficar refém dos compromissos do cliente e causar dano à relação. Explico que atrasos não serão descontados do tempo do cliente seguinte, entretanto, se o atraso for provocado por mim, então eu reponho este tempo. Müller-Granzotto e Müller-Granzotto (2007) concordam que os atrasos:

(...) devem ser religiosamente descontados do tempo contratado para cada sessão (...). A recíproca, entrementes, não é verdadeira. O retardo do clínico deve ser ressarcido, uma vez que, durante o período que estava atrasado, o clínico não se ocupava do consulente. Portanto, não é ético que o clínico considere terapêuticos os atrasos que ele próprio provocou (p.321).

Cláusula 6: “A sessão poderá ser remarcada toda vez que o cliente comunicar, com o mínimo de 5 horas de antecedência, a impossibilidade de comparecer. As sessões realizadas às segundas-feiras deverão ser avisadas até às $10 \mathrm{~h}$ da manhã. Ultrapassando estes prazos a sessão será cobrada";

Comentários: se o cliente avisar com até 5 horas de antecedência, poderá ser encontrado outro horário, embora não haja a obrigatoriedade desta sessão ser imediatamente reposta porque o horário foi combinado previamente, ainda na negociação do contrato.

Para registrar estas remarcações, presenças, faltas e pagamento, ao fim do mês, a secretária preenche uma ficha de acompanhamento chamada Controle de atendimento (ver Anexo 2), e seu preenchimento se inicia após o fechamento do contrato verbal, quando inclusive é mostrada ao cliente.

O cliente, ao chegar para o atendimento, encontrará redigido na ficha à data e a sessão a que se refere no mês para rubricar no espaço destinado. Quando ele não pode comparecer, mas avisa com a antecedência combinada, a secretária imediatamente escreve "repor", para ser rubricado quando vier para a sessão seguinte. Este procedimento dá ciência de que a sessão será reposta. Quando combinada uma data para fazer esta sessão, estará escrito "reposição" e não será mais computada, pois ela foi cobrada no mês em que deveria ter sido realizada.

Quais as vantagens que vejo nisto? Primeiramente, é uma das formas de exercermos o cuidado e o controle sobre o lado objetivo do tratamento. Em segundo, os clientes tomam conta do que está escrito e do que assinam e assumem a responsabilidade pelas suas ações. Em terceiro, é um registro do seu funcionamento no processo terapêutico e pode ser aproveitado nas sessões para relacionarmos, por exemplo, períodos de maior resistência expressa com o aumento de faltas, outros de maior sofrimento com pedidos de sessões extras, o tempo de tratamento etc.
Cláusula 9: "O reajuste é anual";

Comentários: não tenho muita disponibilidade para reduzir o preço dos meus honorários, porém se um cliente pede algum desconto no valor cobrado e concedo, então proponho um reajuste semestral.

Um ponto relevante sobre esta cláusula é que o medo da perda do cliente pode levar o terapeuta ao adiamento do reajuste e, neste caso, infringir o acordo estabelecido e correndo o risco de dano à relação.

Müller-Granzotto e Müller-Granzotto (2007) ponderam com relação aos honorários dizendo que:

(...) o valor da sessão em verdade paga o quanto o profissional "deixa” o consulente trabalhar. Gestaltterapeutas que têm dificuldade para valorar e cobrar o seu próprio trabalho (seja para mais ou para menos) não apenas depreciam ou supervalorizam seu ofício. Eles também conspiram contra a orientação ética do tratamento (p. 324).

E, ainda, com relação à questão da valoração do trabalho terapêutico, afirmam:

(...) se o pagamento remunera o "quanto de autonomia" os clínicos asseguram aos seus consulentes, a falta de cobrança ou a cobrança de um valor menor (ou, em alguns casos, maior) demarca a resistência destes clínicos em favorecer a "alforria" de seus acompanhados. Ou, ainda, (...) demarca o apego dos clínicos ao lugar de poder a que foram conduzidos pelo "apelo" dos consulentes (p. 325).

Comumente utilizando o termo consulente, esses autores pontuam uma diferença no uso das demais palavras usualmente empregadas na literatura gestáltica, "cliente" ou, menos frequente, "paciente". Segundo eles, "o consulente não é um 'cliente', que paga por um serviço. Menos ainda um 'paciente', assujeitado a um saber médico, psicológico, jurídico, filosófico” (2007, p. 324). Para eles, consulente "é aquele que vem ao nosso consultório fazer uma consulta sobre algo que se passa consigo na esperança de que possamos intervir em seu favor.” (D`Acri, Lima \& Orgler, 2007, p. 24, nota de rodapé).

Em contrapartida, o clínico, termo que empregam para o terapeuta, é o interlocutor que permite ao consulente "aperceber-se, tomar posse de seu próprio fluxo de awareness, ou do modo como o interrompe" (MüllerGranzotto \& Müller-Granzotto, 2007, p. 324).

Não obstante, os dados que possibilitam a convivência numa sociedade objetiva, tais como: emissão de recibos, contratos civis, prestação de serviço representam o outro lado da moeda, com o qual é necessário lidar, "mas não é algo com que o clínico deva operar quando efetivamente se ocupa do consulente" (Müller-Granzotto \& MüllerGranzotto, 2007, p. 324). 
Cláusula 10: "Quando as férias do cliente não coincidirem com as do terapeuta, o primeiro pagará as sessões normalmente no mês de suas férias, porém, posteriormente, serão repostas como extras, de acordo com a necessidade do próprio cliente."

Comentários: as sessões serão repostas de acordo com a escolha do cliente, portanto eles regulam esta reposição.

Os meses de janeiro, fevereiro e julho são aqueles que normalmente o brasileiro goza as suas férias. $\mathrm{O}$ terapeuta não pode ficar refém disto, sua vida não pode parar por conta de convenções e nem se angustiar por que os clientes tiraram férias e que, por isto, não saberá como pagar suas contas. Não há uma combinação de que há férias do processo terapêutico, ou como ouvi certa vez de uma cliente ao explicar esta cláusula: "não há trancamento", referindo-se ao trancamento de matrícula nos cursos universitários. Sendo assim, o cliente pagará normalmente no período em que for se ausentar sabendo que serão repostas, conforme desejar. Em contrapartida, como todo trabalhador, o terapeuta poderá requerer alguns dias de descanso, mas para isso fará todo um planejamento. Portanto, suas férias deverão ser projetadas com antecedência de forma que o cliente possa até conciliar com as dele.

Lima Filho (1995) aponta para uma questão importante quanto ao sentimento causado pela ausência do terapeuta: "há uma relativa separação que dá margens a muitas fantasias e sentimentos que, se considerados, enriquecerão bastante o conteúdo das sessões" (p.84). Desta forma, além de se incluir o item férias na formulação do contrato, recomenda ao terapeuta "retomar o assunto, quando as datas puderem ser definidas, (...) para que o cliente possa se organizar e conviver com aquela falta" (p.84).

Diante do conhecimento de que alguns terapeutas cobram suas próprias férias dos seus clientes, sem reposição destas sessões, deve-se atentar que quando se escolhe uma profissão autônoma, o profissional assume o ônus e bônus e, por conseguinte, precisa encontrar uma maneira de planejar seu descanso sem cobrar por um serviço não prestado.

Cláusula 11: "Não há um prazo pré-estabelecido para o término do tratamento;"

Comentários: é esclarecido que a alta é dada pelo cliente e não pelo terapeuta. Se o cliente precisar da autorização do terapeuta para ir embora é porque não tem autossuporte. Este ponto é de suma importância porque um cliente poderá retardar sua autonomia pelos ganhos que está tendo na relação com o terapeuta. E o terapeuta precisa rever suas necessidades para perceber se não está contribuindo para isto, por exemplo, pelo medo de perder o cliente e assim ser desastroso na sua vida pessoal.

Müller-Granzotto e Müller-Granzotto (2007) concordam que "cabe ao consulente, portanto, (...) decidir pelo fim do processo terapêutico" (p.321). O terapeuta precisa estar em contato com a forma que contribui para a evitação do cliente e do dizer adeus.

Cláusula 12: "Solicita-se ao cliente que comunique pessoalmente ao terapeuta, se houver a necessidade de interromper o tratamento".

Comentários: explica-se que um processo terapêutico passa por diversos momentos e alguns comportamentos são inerentes a alguns deles, como, por exemplo, a vontade de faltar ou de sair - muitas vezes após um período de muita mobilização ou de resistência. Peço que na medida do possível, possa vir e falar da sua vontade de faltar ao invés de faltar.

É facultado ao cliente o direito de interromper o tratamento uma vez que queira, mesmo que o terapeuta não concorde com a decisão. Quando se trabalha e respeita a decisão do cliente de interromper o processo, seja por que motivo for, alguns não saem, outros retornam e há aqueles que encerram mesmo.

Concluindo, a combinação verbal não perde a sua importância, em relação ao contrato escrito. Sendo assim, algumas questões poderão ficar de fora do contrato escrito porque serão combinadas ao longo do processo, ou por tratarem de detalhes muito específicos de um cliente. Um exemplo de cláusula que não costumo redigir, apenas combino, diz respeito ao número de sessões combinadas inicialmente e o direito do cliente de pedir para aumentar ou diminuir este número uma vez que deseje. Neste ponto específico Müller-Granzotto e MüllerGranzotto (2007) também concordam que "cabe ao consulente, portanto, aumentar ou espaçar a distância entre as sessões." (p. 321).

\section{Considerações Finais}

Não se deve perder de vista que este trabalho está focado nos primeiros encontros entre os pretensos terapeuta e cliente, mais precisamente no período que compreende o fechamento do contrato terapêutico. Segundo a autora, o que acontece nestes momentos iniciais será importante para os rumos que irão tomar sendo, por isto, que alguns cuidados se fazem necessários na construção desta relação.

Um contrato claro e explícito proporciona um sinal de cuidado e de abertura para a comunicação. Limites bem definidos e regras claras são orientações para uma boa educação, logo poderão também servir de fundamentos para a construção da relação terapêutica. O cliente poderá vislumbrar um espaço de confiança, o que contribuirá para a fluidez do processo psicoterápico.

De acordo com o conceito de autorregulação organísmica, preconizado pela Gestalt-terapia para a orientação do funcionamento saudável do ser-no-mundo, o terapeuta, assim como qualquer pessoa, busca na interação com 
o meio a satisfação de suas necessidades. Desta forma, confrontando os motivos que o estão levando a aceitar o cliente que está entrevistando com as necessidades atuais de sua vida, o terapeuta aumentará a consciência de si mesmo a fim de discernir o que de forma ética poderá buscar de satisfação nesta relação.

Ademais, ao longo deste processo, o contrato terapêutico poderá ser utilizado também como um regulador da relação e as cláusulas deverão ser revistas e atualizadas toda vez que o terapeuta e/ou o cliente perceberem que há desigualdade na relação, evitando, assim, alguns danos. Com isto, pretende-se que este instrumento assuma uma função a mais do que mera combinação de dados objetivos, conforme comumente empregada.

Face aos poucos trabalhos encontrados na literatura gestáltica sobre este assunto e, menos ainda, sobre uma discussão mais detalhada das cláusulas do contrato terapêutico da forma exposta aqui - com o levantamento de questões delicadas, algumas vezes discutidas somente em pequenos grupos ou com colegas mais íntimos - não é intenção polemizar com certos e errados, mas abrir a possibilidade de uma interlocução mais ampla, principalmente porque o tema é inerente aos terapeutas, que a partir das próprias experiências, poderão confirmar, refutar ou apresentar outras proposições a respeito dos itens discutidos.

\section{Referências}

Casarin, D. (2008). Contato. Rio de Janeiro: Editora Revinter.

Lima Filho, A. P. (1995). O Contrato Terapêutico. Revista de Gestalt, 4, 75-86.

Lima, P. A. (2005). Psicoterapia e mudança - uma reflexão. Tese de Doutorado, Universidade Federal do Rio de Janeiro, Rio de Janeiro.

Müller-Granzotto, M. J. \& Müller-Granzotto, R. L. (2007). Aqui e agora. Em G. D’Acri, P. Lima, \& S. Orgler (Orgs.). Dicionário de Gestalt-terapia - "Gestaltês”. (p. 24). São Paulo: Summus.

Müller-Granzotto, M. J. e Müller-Granzotto, R. L. (2007). Fenomenologia e Gestalt-terapia. São Paulo: Summus.

Perls, F. S. (1980). As tarefas do terapeuta. Em J. Fagan \& I. L. Shepherd (Orgs.), Gestalt-terapia: teoria, técnicas e aplicações (pp. 128-132). Rio de Janeiro: Zahar.

Perls, F. S. (1977). Terapia de grupo versus terapia individual. Em J. O. Stevens (Org.), Isto é Gestalt (p. 33). São Paulo: Summus.

UOL - Michaelis - Moderno Dicionário da Língua Portuguesa [online]. Acesso em 15 de julho de 2007, em http://michaelis.uol.com.br/moderno/portugues.

Yontef, G. M. (1998). Processo, diálogo, awareness. São Paulo: Summus.
Gladys Costa de Moraes Rêgo Macedo D`Acri - Psicóloga, responsável pelo Instituto Terapêutico Corpo e Mente; pós-graduada em Psicopedagogia e Psicossomática Contemporânea; com especialização em Psicoterapia de Crianças e Adolescentes em Gestalt-terapia e em Terapia de Família pelo Instituto Mosaico, Instituto de Terapia de Família e com Teresinha Mello da Silveira; idealizadora e organizadora do livro Dicionário de Gestalt-terapia - Gestaltês. Email: gladysdacri@globo.com

\section{Anexo 1}

Nome:

Início:

\begin{tabular}{|c|c|}
\hline Tratamento & Valor por sessão \\
\hline Psicoterapia & $\mathrm{R} \$ 000,00$ \\
\hline
\end{tabular}

\section{Contrato De Trabalho Para Psicoterapia}

1) A consulta psicológica tem duração de até 60 minutos;

2) O cliente deverá efetuar o pagamento das sessões ao final do mês vigente ou na data acertada por ocasião da combinação do contrato terapêutico;

3) Caso haja necessidade de alterar ou transferir a data do pagamento, o cliente deverá comunicar previamente ao terapeuta durante a sessão;

4) O cliente paga por um horário regular previamente combinado com seu terapeuta, por isto é cobrado mesmo em caso de falta justificada;

5) Não há possibilidade de desmarcar a sessão, apenas remarcar, pois o cliente assume o compromisso semanal de estar com o terapeuta;

6) A sessão poderá ser remarcada toda vez que o cliente comunicar com o mínimo de 05 horas de antecedência do início da sua sessão, a impossibilidade de comparecer. As sessões realizadas às segundas-feiras deverão ser avisadas até as 10h da manhã. Ultrapassando estes prazos, a sessão será cobrada;

7) Quando a sessão coincidir com um feriado, o terapeuta poderá oferecer a seu cliente um outro horário, caso tenha algum disponível;

8) Na impossibilidade do terapeuta atender ao seu cliente, a sessão não será cobrada. Se o cliente desejar a reposição será combinado um horário extra quando, então, será cobrada;

9) O reajuste é anual;

10) Quando as férias do cliente não coincidirem com as do terapeuta, o primeiro pagará as sessões normalmente no mês de suas férias, porém, posteriormente, serão repostas como extras, de acordo com a necessidade do próprio cliente;

11) Não há um prazo pré-estabelecido para o término do tratamento;

12) Se houver a necessidade de interromper o tratamento, solicita-se ao cliente que comunique pessoalmente ao terapeuta;

13) Durante o processo terapêutico, por qualquer uma das partes, poderá ser proposta a necessidade de alteração neste contrato de trabalho.

Data:

De acordo:

$$
\text { Cliente }
$$$$
\text { Gladys D'Acri }
$$ 


\section{Anexo 2}

Controle de Atendimento

Cliente:

Início:

\begin{tabular}{|c|c|c|c|c|c|}
\hline Data & $\mathrm{N}^{0}$ sessão & Repor? & Sessões de reposição & Horário da ligação & Rubrica \\
\hline & & & & & \\
\hline & & & & & \\
\hline & & & & & \\
\hline & & & & & \\
\hline & & & & & \\
\hline & & & & & \\
\hline & & & & & \\
\hline & & & & & \\
\hline & & & & & \\
\hline & & & & & \\
\hline & & & & & \\
\hline & & & & & \\
\hline & & & & & \\
\hline & & & & & \\
\hline & & & & & \\
\hline & & & & & \\
\hline & & & & & \\
\hline & & & & & \\
\hline & & & & & \\
\hline & & & & & \\
\hline & & & & & \\
\hline & & & & & \\
\hline & & & & & \\
\hline
\end{tabular}

Recebido em 11.02.09

Primeira Revisão Editorial em 25.05.09

Aceito em 12.10.09 